\title{
Research on Measures of Prevention Against Network Telecommunication Fraud in a University
}

\author{
Zhangliao $\mathrm{Xu}^{1}$, Xisong $\mathrm{Miao}^{1,{ }^{*}}$, Huanyu $\mathrm{Wei}^{1}$, Jun $\mathrm{He}^{1}$ and Qing Xiu ${ }^{2}$ \\ ${ }^{1}$ School of Information Engineering, Kunming University, Kunming, Yunnan 650214, China \\ ${ }^{2}$ School of Medicine, Kunming University, 650214 Kunming, China \\ *Corresponding author.Email:48416017@qq.com
}

\begin{abstract}
This paper aims to analyze the common types of telecom network fraud and its most frequent causes in colleges and universities. By taking a university as an example, the characteristics and causes of telecom network fraud in Colleges and universities are analyzed and measures on its prevention are put forward. . A stratified random sampling method was used to investigate the students in a university by using the telecom fraud questionnaire compiled by Tencent star. The results show that the incidence of fraud among college students in Kunming, Yunnan Province was 14.68\%. Furthermore, among the 10 factors, the occurrence of fraud was related to fraud of chatting with beautiful nakedgirls $(\mathrm{P}<0.05)$ and red envelope rebate fraud $(\mathrm{P}<$ $0.05)$. Therefore, the overall incidence of fraud among college students is high, and targeted guidance can be given to college students according to the influencing factors.
\end{abstract}

Keywords: telecom network fraud, Stratified random sampling, Preventive research, measures

\section{INTRODUCTION}

In 2020, Nanjing Public Security Bureau summarized 58 common telecom network fraud cases under 9 broad types, which shows that telecom network fraud crimes in China are increasing [1]. Therefore, this paper makes a relevant investigation on the phenomenon of "Telecom fraud" suffered by college students in a university. According to the analysis of the questionnaire results, it can be seen that the causes of this fraud are multifaceted. Therefore, this paper puts forward some measures to strengthen the prevention of "Telecom fraud" by establishing their own prevention awareness, family education, college publicity and correct guidance prevention.

\section{OBJECT AND METHOD}

\subsection{Participants}

3050 students in a university in Kunming, Yunnan Province.

\subsection{Method}

\subsubsection{Sampling method}

The stratified random sampling method was used to investigate the students in a university.

\subsubsection{Investigation methods}

The self-made questionnaire of Telecom fraud was used for investigation. After being processed in Excel, this questionnaire was analyzed by SPSS 19,0 statistically. The questionnaire includes the basic information of students and 10 common fraud methods. The school's basic information includes gender, age, educational background, discipline, place of origin, grade, and living expenses. The 10 common fraud methods are: online part-time click farming, online dating induced gambling, impersonating public security, naked chat with beautiful women, online loans, false illegal SMS links, investment and financial management, impersonating acquaintances and impersonating customer service. The form of the self-made Telecom fraud questionnaire is yes-no question When your answer is "yes", you can get 1 point, and the answer is "no", you can get 2 points. . The reliability and validity of the self-made Telecom fraud questionnaire are 0.798 and 0.911 .

\subsection{Data Collection Method}

Tencent questionnaire star is used to make an electronic questionnaire. The questionnaire is anonymous with consistent instructions. However, the principals of each college will publish them in the class QQ group and WeChat group, and organize students to fill in and submit them. 3050 questionnaires were distributed and 3000 were collected, with a recovery rate of $98.36 \%$, among which 2936 questionnaires are valid, with the effective rate of $97.87 \%$. 


\subsection{Statistical Treatment}

SPSS 19.0 was used for statistical analysis. The counting data is expressed as a percentage using $\chi 2$ Inspection to analyze. In addition, the method of entering in multiple logistic regression analysis is adopted to test the significance of common fraud patterns, which is statistically significant as $\mathrm{P}<0.05$.

\section{RESULTS}

\subsection{General Information of Respondents}

2936 valid questionnaires were submitted, including 1150 boys $(39.17 \%)$ and 1781 girls $(60.66 \%)$, aged from 17 to 25 years. 834 students are freshmen $(28.41 \%), 818$, sophomores $(27.86 \%), 793$, juniors $(27.01 \%)$ and 471 , seniors $(16.04 \%), 12$, postgraduates in the first year $(0.41 \%)$ and 8 , postgraduates in the second year $(0.27 \%)$. Among the students, 2916 are undergraduates and 9 are masters. The information for the number of people surveyed in 13 disciplines is as follows: 59 in philosophy, 19 in economics, 76 in law, 36 in pedagogy, 41 in literature, 1 in history, 197 in science, 1074 in engineering, 10 in agriculture, 704 in medicine, 14 in military science, 80 in management and 625 in art. There are 627 students from urban and 2309 from rural areas.

\subsection{The Information for Student Who Suffered from Fraud}

Among 2936 students, 2503 (85.25\%) were never cheated, $302(10.29 \%)$ were cheated once, and $131(4.46 \%)$ were cheated twice or more. The incidence of fraud was $17.32 \%$ (200 / 1155) for boys and 13.19\% (235 / 1781) for girls. There was significant difference between boys and girls, $\chi$ $2=6.944152, \quad \mathrm{P}=0.008409(\mathrm{P}<0.05)$.

\subsection{Comparison of Fraud Incidence in different Grades and Educational Background}

The analysis of questionnaire statistical results shows that the probability of senior students' being defrauded is slightly higher than that of the other three grades, followed by sophomore, freshman and junior, but there is no statistical significance in the incidence of fraud for students in different grades $(\mathrm{P}>0.05)$, and the probability of graduates' being defrauded is slightly higher than that of undergraduates, but there is no statistical significance by comparing these two figures $(\mathrm{P}>0.05)$, as shown in Table 1 .

Table 1. Comparison of the incidence of fraud in different grades and educational levels (n)

\begin{tabular}{|c|c|c|c|c|}
\hline Grade & Number of respondents & Incidence of fraud(\%) & $X^{2}$ & $P$ \\
\hline Freshmen & 834 & 14.15 & 0.140 & 0.708 \\
\hline Sophormore & 818 & 15.40 & 0.253 & 0.615 \\
\hline Junior & 793 & 13.75 & 0.415 & 0.520 \\
\hline Senior & 471 & 15.92 & 0.428 & 0.513 \\
\hline graduates in the first year & 12 & 16.67 & 0.028 & 0.868 \\
\hline graduates in the second year & 8 & 12.50 & 0.023 & 0.879 \\
\hline Total & 2936 & 14.68 & 1.287 & 0.257 \\
\hline education background & Number of respondents & Incidence of fraud & $X^{2}$ & $P$ \\
\hline undergraduate & 2916 & 14.68 & 0.215 & 0.461 \\
\hline postgraduate & 20 & 15.00 & 0.101 & 0.113 \\
\hline Total & 2936 & 14.68 & 0.316 & 0.574 \\
\hline
\end{tabular}

\subsection{Comparison of the Incidence of Fraud among Students from Different Place of Birth}

The statistical results show that the incidence of fraud of students from cities is slightly higher than that of students from rural areas. Still, with a comparison with these twopart, there is no statistical significance $(\mathrm{P}>0.05)$, as shown in Table 2.

Table 2. Comparison of the incidence of fraud among students from different places of origin (n)

\begin{tabular}{|c|c|c|c|c|}
\hline Place of birth & Number of respondents & Incidence of fraud(\%) & X2 & P \\
\hline Urban area & 627 & 15.95 & 0.529 & 0.467 \\
\hline Rural area & 2309 & 14.42 & 0.146 & 0.703 \\
\hline Total & 2936 & 14.68 & 0.674 & 0.412 \\
\hline
\end{tabular}




\subsection{Comparison of Fraud Rates among Students of Different Disciplines}

The results show that the incidence of fraud among students of philosophy and military science is higher than that of other disciplines, and the incidence of fraud among students of history and agronomy is lower. The incidence of fraud among students of various disciplines is statistically significant $(\mathrm{P}<0.05)$, as shown in Table 3.

Table 3. Comparison of the incidence of fraud among students of different disciplines (n)

\begin{tabular}{|c|c|c|c|c|}
\hline Discipline category & Number of respondents & Incidence fraud(\%) & $\mathrm{X} 2$ & $\mathrm{p}$ \\
\hline Philosophy & 59 & 20.34 & 1.039 & 0.308 \\
\hline Economics & 19 & 36.84 & 4.596 & 0.032 \\
\hline Law & 76 & 26.32 & 5.459 & 0.019 \\
\hline Pedagogy & 36 & 11.11 & 0.291 & 0.590 \\
\hline Literature & 41 & 12.20 & 0.161 & 0.688 \\
\hline History & 6 & 0 & 0.885 & 0.347 \\
\hline Physics & 197 & 14.21 & 0.033 & 0.855 \\
\hline Engineering & 1074 & 14.99 & 0.037 & 0.847 \\
\hline Agriculture & 10 & 10.00 & 0.139 & 0.709 \\
\hline Medicine & 710 & 13.80 & 0.378 & 0.539 \\
\hline Military & 3 & 33.33 & 0.527 & 0.468 \\
\hline Management & 80 & 18.75 & 0.732 & 0.392 \\
\hline Art & 625 & 12.96 & 1.199 & 0.273 \\
\hline Total & 2936 & 14.68 & 15.477 & 0.00008 \\
\hline
\end{tabular}

\subsection{Analysis of Influencing Factors on the Incidence of Fraud Suffered by Students}

Possible influencing factors of common fraud among school students, such as fraud of online part-time click farming, online dating induced gambling, fraud of pretending to be government staff, fraud on chatting with naked beautiful girls, online loan fraud, fake illegal SMS links, investment and financial fraud, fraud of pretending to be acquaintances, fraud of pretending to be customer service, red envelope rebate fraud, etc. Multi-factor analysis is carried out on these aspects, and logistic regression model is adopted, thus the selected variables are online part-time click farming, online dating induced gambling, impersonating public security, fraud on chatting with naked beautiful girls, online loan fraud, fake illegal SMS links, investment and financial fraud, fraud of pretending to be acquaintances, fraud of pretending to be customer service and red envelope rebate fraud. Taking whether to be cheated as the dependent variable and 10 influencing factors of fraud as the independent variable, the logistic regression analysis was carried out by using relevant tools, and the single meaningful factor was included into the multiple factors. The analysis results were as follows: fraud in chatting with naked beautiful girls $(\mathrm{P}=0.001)$ and red envelope rebate fraud $(\mathrm{P}=0.002)$ were the independent influencing factors of sleep quality fraud. There are no other related factors, see Table 4.

Table 4. Logistic regression analysis results of influencing factors of cheating among students in school

\begin{tabular}{|c|c|c|c|c|}
\hline \multirow{2}{*}{ Influence factors } & \multicolumn{2}{|c|}{ Single-factor analysis } & \multicolumn{2}{|c|}{ Multi-factor analysis } \\
\cline { 2 - 5 } & OR $(95 \% \mathrm{CI})$ & $\mathrm{P}$ & OR $(95 \% \mathrm{CI})$ & $P$ \\
\hline Fraud of online part-time click farming & $0.179(1.356 \sim 1.535)$ & 0.000 & $1.194(0.522 \sim 1.716)$ & 0.357 \\
\hline Online dating induced gambling & $0.098(1.237 \sim 1.335)$ & 0.005 & $1.329(0.632 \sim 1.961)$ & 0.359 \\
\hline Pretending to be government staff & $0.076(1.217 \sim 1.293)$ & 0.047 & $1.171(0.539 \sim 1.71)$ & 0.791 \\
\hline Fraud of chatting with naked beautiful girls & $0.078(1.218 \sim 1.296)$ & 0.040 & $1.011(0.394 \sim 1.405)$ & 0.001 \\
\hline Fraud of online loan & $0.103(1.257 \sim 1.360)$ & 0.000 & $1.198(0.454 \sim 1.652)$ & 0.722 \\
\hline Fake illegal SMS links & $0.079(1.215 \sim 1.294)$ & 0.061 & $1.029(0.379 \sim 1.408)$ & 0.940 \\
\hline Investment and financial fraud & $0.075(1.216 \sim 1.291)$ & 0.048 & $1.564(0.589 \sim 2.153)$ & 0.464 \\
\hline Fraud of pretending to be acquaintance & $0.094(1.200 \sim 1.294)$ & 0.270 & $1.194(0.522 \sim 1.716)$ & 0.678 \\
\hline Fraud of pretending to be customer service & $0.083(1.220 \sim 1.303)$ & 0.032 & $1.324(0.558 \sim 1.882)$ & 0.899 \\
\hline Fraud of red envelope rebate & $0.091(1.216 \sim 1.307)$ & 0.057 & $0.610(0.201 \sim 0.811)$ & 0.002 \\
\hline
\end{tabular}




\section{DISCUSSION}

\subsection{Fraud Prevention for Students in a University}

This survey shows that the incidence of fraud among students in a university in Kunming, Yunnan Province is $14.68 \%$, indicating that the incidence of fraud among students in a university is high and the overall awareness of prevention is poor. They may not use legal weapons reasonably to safeguard their own interests. In addition, students have more free time in colleges, which is easy to breed inert ideas, thus making them become victims of fraud. In addition to irregulardaily eating and living habits they have more chances to be exposed to new things, so they may not resist the temptation of the outside world. Secondly, college students do not fully protect their personal information. From the gender difference of fraud, the incidence of fraud in boys is significantly higher than that in girls, which may be related to practical problems such as boys' immature mind. The statistical analysis of the survey results shows that there is no obvious relationship between the incidence of fraud and the grade, educational level and place of birth of students.

\subsection{Factors Affecting the Incidence of Fraud among Students in a University}

Multiple logistic regression was used to analyze the influencing factors of fraud incidence. The survey showed that among the 10 factors, fraud was related to the fraud of chatting with beautiful naked girls $(\mathrm{P}=0.001)$ and red envelope rebate fraud $(\mathrm{P}=0.002), \mathrm{P}<0.05$. Most of the college students in a university are born in the "post-95" and "Post-00". Spoiled by their parents, they encounter few setbacks in their daily life. so they are easy to be panic and irrational in case of anything. In addition, they are unwilling to communicate with counselors, teachers, classmates and even parents. In this case, most college students pay directly, resulting in being cheated and failing to improve their vigilance and prevention.

\subsection{Countermeasures to Prevent Fraud in Colleges and Universities}

\subsubsection{Self-prevention for College Students}

No pain, no gain.College students should firmly believe that there is no free lunch.. Only hard work can pay off. As people with higher education, college students are sometimes too confident, believing they will not be cheated. It can be said that there are always weaknesses in human nature. We need to constantly learn new fraud "means" from others in order to protect our own personal property. At the same time, we must maintain a correct concept of consumption and good interpersonal habits, refuse unconventional fraud means such as campus loan, naked loan and violent chats, and invest more time and energy on our own interests and hobbies.

\subsubsection{Head teachers and counselors cooperate to prevent against fraud}

It should regularly carry out anti-fraud class meetings and anti-fraud activities, and encourage students to actively participate in them. In addition, they should consolidate the students' psychological security defense line, educating them not easily trust online part-time jobs, online rebates for click farming and unfamiliar telephone messages. In case of this situation, students should timely feed back to the head teacher and counselor. Moreover, they should educate students not to reply to any fraud information or just ignore them directly, so as to prevent fraud gangs to make further setting traps; At the same time, teachers should educate students to flexibly and reasonably use the law to safeguard their legitimate interests. If students are cheated, they should not let it go or comfort themselves by saying experience must be bought". They should actively use legal weapons to fight fraudsters.

\subsubsection{The college should publicize the prevention against fraud in an all-round manner}

The college can establish a complete set of anti-fraud system and countermeasures. In daily life, the college should actively carry out anti-fraud publicity and recruit volunteers to enter the dormitory for anti-fraud publicity in order to let every students get familiar with the anti fraud concept. We should properly use WeChat official account, micro-blog and other social platforms, regularly update fraud cases and routines. In the meantime, it should regularly carry out anti -raud knowledge test and questionnaire survey every year, and focus on the students whose analysis results are dangerous. The college shall conduct publicity according to professional characteristics and set up funds for anti-fraud publicity activities, such as making some anti-fraud slogans printed on mouse pads and door stickers.

\subsubsection{Strengthening information protection}

Some websites of colleges and universities are constructed in an early time, thus there are great loopholes to allow criminals to take advantage of. The information security protection should be strengthend in telephone cards issued by the school and the students' personal information. The staff of relevant departments must pay attention to the student information and change the system password regularly to maintain student information security. Students personal bank cards, ID cards and express delivery 
information shall be replaced and destroyed regularly to avoid traps set by criminals.

\subsubsection{College students should improve their discrimination ability and increase their experience}

In the publicity process, although some slogans are absolute, only by emphasizing the seriousness of things can we leave deep impression on the students' minds. Only by constantly learning "new routines" and "new means" of fraud can we keep a clear mind and sharpen the eyes blinded by the network. We should be very cautious about false information. No matter what happens, we should ensure our personal safety the first time. In the face of the threats and inducements of fraudsters, we should call the police in time, listen to the suggestions of teachers and police and deal with them properly.

\subsubsection{Laws and regulations related to university fraud are not perfect}

There is no shortage of liars in any era. With the escalating means of fraudsters, the target people are not fixed, the casesolving rate is not high, the speed of legislation is slow, and there is weakness in the enforcement.

\subsubsection{Social level}

In society, we should create a good social atmosphere and establish a correct three outlooks. We should condemn those illegal fraudsters and fraud gangs. For young students, we should not only take the initiative to establish an anti-fraud firewall, but also create a good social atmosphere for young students, which requires the joint efforts of many parties.

To sum up, this survey which investigates and analyzes the characteristics and causes of network telecommunications fraud in a university in Yunnan Province, is a relatively comprehensive research on the occurrence of college fraud in the current survey of colleges and universities in Yunnan Province. The self-made telecommunications fraud questionnaire contains most of the factors that college students are cheated. Therefore, it has good reliability and validity, and can provide a reference for the research on fraud prevention in colleges and universities.

\section{CONCLUSION}

College students must maintain a correct concept of consumption and good interpersonal communication habits, refuse campus loans, naked lending, chatting and other unconventional fraud means, put more time and energy on their own interests and hobbies.

Class meetings and activities with the theme of fraud prevention will be held regularly by the head teachers and counselors to encourage students to take an active part in them and consolidate their psychological safety lines.

Colleges should actively carry out anti-fraud propaganda and recruit volunteers to enter the dormitory for anti-fraud propaganda to leave a deep impression on every student's mind..

We should create a good social atmosphere and set up the correct three outlooks for young students at the social level.

\section{ACKNOWLEDGMENT}

This paper is fund by National New Engineering Research and Practice Project (e-jsjrj20201342), National Natural Science Foundation of China (62066023).

\section{REFERENCES}

[1] LV Meichen. Theoretical research on the prevention of telecom network fraud -- from the perspective of situational crime prevention theory. Journal of Beijing Police College, 2020 (9): 96-103.

[2] Wang Jie. Investigation on the effectiveness of judicial control of telecom network fraud [J]. Chinese Journal of criminal law, 2020 (1): 167.

[3] Ge Yiting, Wang Panpan, Kessel Kurban. Psychological analysis and coping strategies of college students cheated by Internet fraud. Psssychological monthly, 2020 (11): 30-31.

[4] Tao Hualin, Yang Jiawei, Zhang Ziyin, Jia Zheng, Cai Jin. New features and Countermeasures of Telecom fraud. Science and technology entrepreneurship monthly, 2016 (12): 104-106.

[5] Li Yuting, Li Lingzhi, Xu Xingyue, Cao Liyuan, Li Xiaopeng. Research on the causes and preventive measures of "Telecom fraud" among undergraduates in Colleges and Universities -- Taking Gansu Agricultural University as an example. Legal system Expo, 2020 (12): 179-180. 